Informal Report

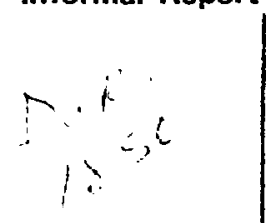

UC-79p

Reporting Date: September 1975 Issued: November 1975

\title{
Preliminary Topical Report on
}

\section{Comparison Reactor Disassembly Calculations}

by

T. P. McLaughlin

IOS ALAMOS, NEW MEXICO 87545<smiles>[3H][13CH][13CH][13CH]</smiles>

An Alfirmative Aclion/Equa! Opportunity Employer 
In the interest of prompt distribution, this report was not edited by the Technical Information staff.

Work supported by the U. S. Energy Research and Development Administration. Division of Reactor Research and Development, Program No. D554.

Printed in the United States of Amorica. Available trom

National Technical Information Service

US Deparimont of Commorce

5285 Port Royal Rand

Springtield VA 22151

Price: Printed Copy \$1.00 Microtiche \$2.25

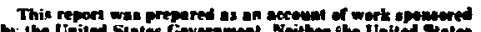

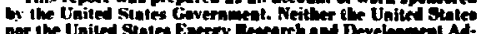

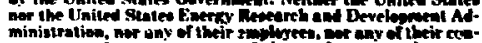

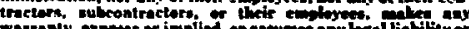

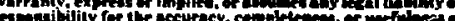

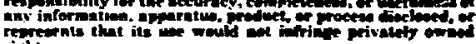

rikhts. 


\section{ABSTRACT}

This report describes preliminary results of comparison disassembly calculations for a representative LMFBR model (2100$\ell$ voided core) and arbitrary accident conditions. The analytical methods employed were the computer programs: FX2-POO,, PAD, and VENUS-II. Calculations were performed at Argonne National Laboratory, Brigham Young University, and Los Alamos Scientific Laboratory. The calculated fission energy depositions are in good agreement, as are measures of the destructive potential of the excursions, kinetic energy, and work. However, in some cases the resulting fuel temperatures are substantially divergent. Differences in the fission energy deposition appear to be attributable to residual inconsistencies in specifying the comparisun cases. In contrist, temperature discrepancies probably stem from basic differences in the energy partition models inherent in the codes. Although explanations of the discrepancies are being pursued, the preliminary results indicate that all three computational methods provide a consistent, global characterization of the contrived disassembly accident.

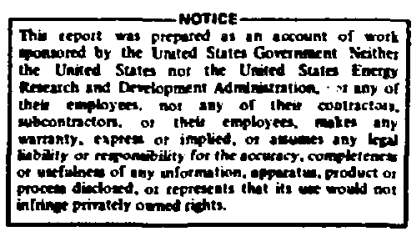




\section{INTRODUCTION}

The calculation of standard problems by different groups and with different methods is a widely practiced technique for improving understanding of and confidence in various analytical methods. This report describes preliminary results of comparison analyses of hypothetical core disruptive accident conditions. The specific area of interest is that regime of the postulated accident which is analyzed by a disassembly code, e.g., VENUSII.

The initial impetus for this study was provided by $W . R$. Stratton of the LASL. Subsequently, a meeting was held in the spring of 1975 to discuss the feasibility and utility of such calculations as well as to specify the ground rules, if accord was reached that such would be practical and beneficial. At that meeting it was decided that the exercise would be worthwile for (at least) the following reasons.

- Although gross disagreement was not expected, documentation of a comprehensive comparison did not exist.

- Should serious disagreements arise, these would indicate areas where differences in the calculational models are signiflcant and possibly areas where experiments are required.

- Reporting of results of disassembly analyses by various 
TABLE OF CONTENTS

ABSTRACT ............................. I

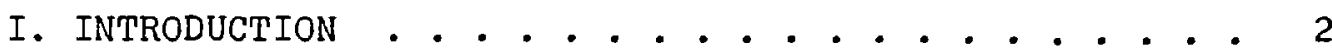

II. ANALYTICAL METHODS ............. . . 4

A. FX2-POOL ............... 5

B. $P A D$............... 7

C. VENUS-II . . . . . . . . . . . . 8

D. Equation-of-State (EOS) Modeling ...... 9

1. Fuel Vapor Pressure .. . . . . . . 10

2. Energy Partition .......... 10

III. MODEL SPECIFICATIONS . . . . . . . . . . 12

IV. RESULTS . . . . . . . . . . . . . . . 18

V. PRELIMINARY CONCLUSIONS . . . . . . . . . 27

VI. FUTURE EFFORTS . . . . . . . . . . . . . 28

REFERENCES ................... 29

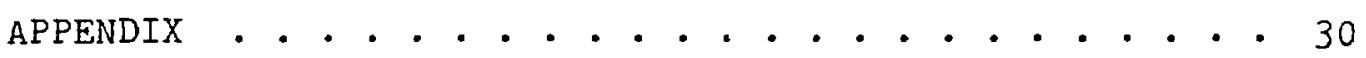


groups has, to date, been inconsistent. In particular the kinetic energy or work, as distinct from the thermal (fission) energy release, has apparently led to misconceptions of the measure of severity of the postulated accident.

The individuals (and their organizations) who expressed in:terest in participating in the actual calculations were:
P. B. Abramson
ANL - AP Div.
C. L. Allen
NRC
J. E. Boudreau
LASL - T-DIV
J. F. Jackson
Erigham Young U.
T. P. McLaughlin
LASL - A-DIV
D. Weber
AliL - RAS Div.

Due to other work commitments and redundancy in the computer codes being employed, C. L. Allen and D. Heber did not contribute to this first round of intercomparisons.

The applicability of the hydrodynamic models in disassemly codes is in general related to the severity of the postuiatec excursion. That is, for mila nuclear explosions such as the KIIIITNT Excursion, it has been possible to calculate significant parameters (fission energy, kinetic energy) to within a factor of 2 of the estimated experimental values. ' On the other hand, postulated LMFBR meltdown accidents, during which material moves but hydrodynamic disassembly does not occur, would not be amenable to analyses by current disassembly codes.

In order to investigate this range of applicability it 
was decided to calculate the agreed upon stanriard problems (based on a $2100-\ell$ volded core model) for input reactivity insertion rates of 20,100 , and $200 \$ / s$. It should be emphasized that these extreme reactivity insertions were contrived solely for intercomparing calculational methods, and are not based on any calculations concerning particular hypothetical accident scenarios. At this time analyses have been performed only for $100 \$ / \mathrm{s}$ reactivity ramps. Upon completion of this phase of the intercomparison study, calculations will be performed for ramps of 20 and $200 \$ / \mathrm{s}$.

For intercomparing analytical meihods, the consensus of those at the aforementioned organizational meeting was that agreement ir total fission energy release within a few tens of percent ( $230 \%$ ) would be both expected and desirable. Setter agreemeni would be encouraging; however, considering the many and basic differences in the geonetric, hydrodynamic, and neutronic models incorporated into these codes, this was not considered necessary for applications to postulated severe recator disassemblies. Of course validation of these codes on an absolute scale is also necessary to insure that although they are internally consistent; they are also complete in the modeling of phenomena.

II. ANALYTICAL METHODS

Four coinputer codes were considered in this first series of calculations. They were:

FX2-POOL 
FX2-VENUS

PAD

VENUS-II

The FX2-VENUS analysis was attempted by P. B. Abramson at ANL. This did not prove feasible for the purpose at hand due to difficulties associated with mesh distortion and mapping.

FX2 requires an Eulerian grid and VENUS employs a Lagrangian grid. As grid distortion (i.e., core disassembly) occurs, the FX2-VENUS technique requires remapping of the distorted (VENUS) grid onto the Eulerian (FX2) grid. Although in principle FX2VENUS can handle this situation, dificulties were encountered. The nature and extent of these difficulties vere not pursued and consequently FXa-VENUS was not employed in any of the comparisons presented in the kesults section of this report.

AlI of the other three analytical methods proved capable of calculating the specified cases at least up to the point of significant mesh distortion or final neutronic shutdown. A review of the basic calculational techniques employed and significant differences among the three codes follows.

\section{A. EX2-POOL}

This analytical tool presents a coupling to the FX2 and POOL computer sodes. $2,3,4$ Both of these programs utilize twodimensional cylindrical $(R-Z)$ geometry and have fixed spatial (Eulerian) grids.

The neutronics are supplied by FX2 which is a space-dependent kinetics treatment based on diffusion treory. Reactivity 
feedback due to both Doppler broadening of the cross sections and displacement (material motion) is treated eagícit $-y$. Eastec on materiaz and temperathre-depercent nise-groug cross-sec: sets, which are prepared a priori, FX2 calculates temperatureadjusted cross sections for each mesh cell. Explicit $k-$ calculations are then performed for determining changes in the state of criticality due to temperature and material motion effects. If there are multiple hydrodynamic time steps per FX2 k-calculation then a quadratic time extrapolation provides the reactivity feedback at each time step.

Thermodynamics and Eulerian hydrodynamics are modeled with POOL, which was developed specifically to analyze boiling pools of fuel and steel. Although this code is capable of treating fuel-steel heat transfer and buoyancy effects, these options were not used.

A limitation on the use of FX2-POOL in this comparison study is:

- The initial delayed neutron precursor concentration must correspond to steady-state conditions at the specified initial power level for the disassembly calculation.

During the analysis of the results presented herein a ratner subtle but significant difference between FX2-POOL and PAD/VENUS-II surfaced. PAD and VENUS-II require as input the prompt neutron lifetime whereas FX2 generates its own. This fact was not recognized when specifying the reactor model, but upon examining of power and reactivity histories it became apparent that there was an inconsistency which a prompt neutron lifetime 
discrepancy could, and did, explain.

Another, substantially less significant, inconsistency in: the pioblem specificaition arose from the fact that FX2-POOL does not accept an input power distribution but uses that resulting from the FX2 k-caleulation. The input power profile for VENUS-II was obtained from earlier criticality calculations for the irtact core model (containing control elemerts and sodium). Therefore power distributions were slightiy inconsistent between these two codes.

B. PAD

This is a coupled neutronics-hydrodynamics program which evolved from computer models developed to analyze weapons explosions, burst reactor (Godiva) transierts, anc later tre ritiTNT reactor destruct experiment. Three one-dimensional geometries (spherical, radial expansion of a cylinder, axial expansion of a cylinder) are available, and the caiculation is performed on a Lagrangian grici.

Doppler reactivity feedback is accounted for by a simple equation of the form:

$$
\mathrm{C}=\mathrm{T}^{\mathrm{n}} \mathrm{dk}, \mathrm{dT},
$$

where $C$ is the Doppler constant (e.g. - 0.004). This equation is evaluated at each time step for each mass point. Thus the Doppler feedback is mass point weighted as in FX2-POOL, but not weighted spatially according to a neutron importance function. Energy deposition and displacement reactivity feedback are provided in a manner similar to FX2-POOL, witr the state of criticality, fluxes, powers, etc., being determined by explicit DTF 
transport calculations. A quadratic time extrapolation between the DTF calculations provides the displacement feedback at each hydrodynamic time step.

\section{VENUS-II}

This is a coupled neutronics-hydrodynamics code developed to analyze postulated LMFBR disassembly accidents. 5,6 Like FK2-POOL, it utilizes two-dimensional $R-Z$ gemoetry, but with Lagrangian hydrodynamics.

Doppler reactivity feedback is calculated via an equation similar to that in the PAD code. The difference is that the change in reactivity due to temperature rise is calculated for zone (mass) averaged temperatures with a weighting coefficient input to each core zone. For the reactor model described in the following section, these weighting factors were 0.55 and 0.45 for the inner and outer core zones, respectively.

Reactivity changes due to material motion are calculated from an input tabulation of spatially dependent reactivity worths. Both reactivity worths and spatial power distributions must be predetermined, i.e., by an R-Z diffusion theory or transport theory calculation.

As previously mentioned this latter point is in contrast to both FX2-POOL and PAD which generate their own flux and power profiles via explicit k-calculatiors. Thus both prompt neutron lifetime and power profile differences were present during these initial calculations.

In future calculations involving these three codes, neutron 
Iifetime differences can be avoided by using the FX2 determined value as input to both PAD and VENUS-II. Power profile differences between FX2 and VENUS-II can similar $1 . y$ be removed. Due to the one-dimensional geometry in PAD it is not possible to model exactly a two-dimensional power profile. However, hydrodynamic and neutronic material densities are separable in PAD and thus the power profile can, if desired, be adjusted to any shape. In particular the PAD calculations in this study had a radial (spherical) power density which matched that radial (cylindrical) power density input into the VENUS-II runs.

D. Equation-of-State-(EOS) Modeling

As with the neutronic and hydrodynamic modeling in these three codes, the thermodynamic models also differ. Given the correctness of the basic hydrodynamic fluid description of the reactor, then the EOS model is probably the least well-founded of all the physIcal models in these disassembly codes. It is important that these be put in perspective.

For LMEBR volded core disassembly analyses such as considered in this study, the energy releases are governed almost entirely by Doppler reactivity feedback. Final neutronic shutdown is provided by material motion which in turn is substantially dependent on the EOS model. However, at the time of significant displacement reactivity feedback the energy deposition is by and large complete.

Another feature of the volded core disassemblies considered is that due to the Doppler reactivity feedback, peak temperatures are not sufficient to cause the fuel to expand, fill all void space, 
and then exert condensed state pressures. Based solely on the coefficient of thermal expansion of molten $\mathrm{UO}_{2}$ near the melting point, the temperature rise needed to expand and fill the space normally cccupied by sodiur would be $\sim 13000 \mathrm{~K}$. Thus for all cases, except possibly those academic cases which had no doppler feedback, hydrodynamic disassembly follows from fuel vapor pressure entirely.

The two areas of the EOS models which then are significant for these calculations are the energy partition and fuel vapor pressure formulations. The latter will be examined first.

\section{Fuel Vapor Pressure}

Both the FX2-POOL and VENUS-II calculations employed the fuel vapor pressure equation associated with the ANL EOS:

$$
P_{V}\left(\text { dynes } / \mathrm{cm}^{2}\right)=\exp \left(69.979-\frac{76800}{T}-4.34 \ell \mathrm{nT}\right) .
$$

The $\mathrm{UO}_{2}$ vapor pressure equation which has been used ir. the PAD coaje for many years is

$$
P_{V}(\mathrm{~atm})=\exp \left(14.77-\frac{53864}{T}\right) .
$$

These two equations are shown in Fig. 1 .

\section{Energy Partition}

Below the melting point of the fuel, the models are essentially identical in all three codes, the energy going into sensible heat according to the general formula

$$
\Delta E=C_{p}(T) \Delta T
$$

At the melt temperature PAD and VENUS-II both have heat sink capabilities to account for the heat of fusion. FX2-POOL 
currently does not have this feature, and therefore heat of fusion is not accunted for.

Above the melting point FX2-POOL and PAD account for the heat of vaporization in similar fashions. VENUS-II analyses were performed with the ANL EOS. 5 The energy-temperature relationship in the latter is based on the prineiple of correspondinE states and does not explicitly account for the heat of vaporization. However, it should be emphasized that this EOS was developed and formulated for applications in the range of fuel energy densities for which heat of vaporization effects are not substantial. 7

Thus, aside from the ANL EOS being different in formalism beyond the melting point, it would be expected that VENUS-II, relative to FX2-POOL and $P A D$, would overpredict the fuel temperature, the magnitude of the overprediction increasing with increasing fuel energy density up to the point of complete vaporization in a celi. An estimate of the temperature rise equivalent of the heat of vaporization is

$$
\Delta \mathrm{T}_{\text {eq }} \approx \frac{\mathrm{L}}{\bar{C}_{\mathrm{p}}} \approx 4000 \mathrm{~K} \text {, }
$$

where approximate values for the heat of vaporization, $L$, and heat capacity, $C_{p}$, are $2000 \mathrm{~J} / \mathrm{g}$ and $0.5 \mathrm{~J} / \mathrm{g}-\mathrm{K}$, respectively. However, considering the basically different energy partition formulations in these codes and the (generally) small mass of fuel vaporized prior to substantial material expansion, this temperature rise equivalent of the heat of vaporization should only be considered as indicative of the trend to be expected in the calculated temperatures when intercomparing results. 


\section{MODEL SPECIFICATIONS}

In deciding upon a physical model, arguments in favor of simple, highly idealized specifications must be weighed against those favoring a more complex geometric/material model. The former would permit a cleaner comparison while the latter would relate more closely to accident scenarios which, although extremely unlikely, have been delineated.

Since these two considerations are not optimized for the same model specifications, the approach taken in defining the system to be calculated was to start from the more complex situation and then simplify it as much as seemed reasonable. For example, since analytical and experimental studies indicate that heat transfer is not an important factor in severe disassembly accidents, it was decided that heat transfer options (available only in FX2-POOL and PAD) would not be used.

The reactor model decided upon is similar to an earlier 2100 liter LMFBR design developed by General Electric. Additionaliy it was specified that the geometry and material distribution correspond to the intact reactor, void of sodium in all regions. Most physical and neutronic specifications for this system are given in the Appendix. A few features not detailed in the Appendix but agreed upon for these comparison calculations are:

- Core Beo and control material is considered as steel, i.e., core steel volume fraction $=0.237+0.048=0.285$.

- No regions will be permitted to support tension, $1 . e .$, structural strength $\equiv 0$. 
- Initial fuel and steel theoretical densities are 9.95 and $7.9 \mathrm{~g} / \mathrm{cm}^{3}$, respectively.

- Fuel heat capacity $=0.548 \mathrm{~J} / \mathrm{g}-\mathrm{K}$, for all temperatures. Note that this was an oversight in that FX2-POOL and VENUS-II both used the ANL EOS value of 0.437 , about $20 \%$ less.

- Any other fuel properties which may be needed are to correspond to $\mathrm{UO}_{2}$, not mixed oxide.

- Delayed neutron precursor concentrations reflect equilibrium conditions at normal operating power, $840 \mathrm{MW}$.

- Initial core fuel temperatures are proportional to the power distribution.

- Initial reflector (blanket) temperatures are constant at $1000 \mathrm{~K}$.

- No fuel-steel heat transfer.

Two sets of initial conditions (reactivity, power, temperature) were agreed upon. The first, case $A$, is a scale up (to $2100 \mathrm{l}$ ) from a SAS flow coastdown analysis for the FTR. Case B represents a nominal power fiducial.

Case A

Reactivity, \$

Power. MW

Av Core Temperature, $\mathrm{K}$

$\begin{array}{cc}1.05 & 1.00 \\ 1.7+06 & 1000 \\ 2500 & 1500\end{array}$


In order to enable comparisons, including the FX2-POOL code, variants of cases $A$ and $B$ were also run. As described in the previcus chapter, FX2-POOL currently requires that initial delayed neutron precursor concentrations correspond to equilibrium conditions at the specified initial power level of the reactor. Moreover, although FX2-POOL will accept any initial temperature distribution, like PAD it has no algorithm (such as VENUS-II has) for having the initial temperatures calculated internally for a specified core average value and a base temperature. Thus for simplicity, those comparison calculations involving FX2-POOL had a flat (spatially independent) initial temperature profile. Additionally, it was decided to run one other variant of these base cases, namely calculations with zero Doppler feedback. These latter analyses were made only to remove a variable in the comparisons and observe the change in agreement, if any, relative to the normal Doppler cases.

For clarity, a summary of the base cases and variations thereof is presented in Table $I$, followed by an intercomparison of these cases in the sequence listed in this table.

\section{A-I: PAD and VENUS-II}

This is the nominal base case A. Differences between the two analyses include:

- Doppler treatment

- $\mathrm{UO}_{2} \mathrm{EOS}$ 
- Geometry, 1-Dimensional spherical vs 2-Dimensional cylindrical

- Power and temperature profiles, this results directly from geometric differences.

\section{A-E: PAD and VENUS-II}

This is identical to case Al with the one exception:

- Doppler $=0.0$.

\section{TABLE I}

OVERVIEW OF COMPARISON CASES

Case Identification Code

\begin{tabular}{llcl} 
A1 & $\begin{array}{l}\text { PAD } \\
\text { VENUS-II }\end{array}$ & -0.004 & $\begin{array}{l}\text { Spatially } \\
\text { dependent }\end{array}$ \\
A2 & $\begin{array}{l}\text { PAD } \\
\text { VENUS-II }\end{array}$ & 0.0 & $\begin{array}{l}\text { Spatially } \\
\text { dependent }\end{array}$ \\
A3 & $\begin{array}{l}\text { FX2-POOL } \\
\text { PAD }\end{array}$ & -0.004 & Flat \\
VENUS-II & PAD & -0.004 & $\begin{array}{l}\text { Spatially } \\
\text { dependent }\end{array}$ \\
B1 & PAD & & $\begin{array}{l}\text { Spatially } \\
\text { dependent }\end{array}$ \\
B2 & VENUS-II & -0.004 & $\begin{array}{l}\text { Spatially } \\
\text { dependent }\end{array}$ \\
B3 & PENUS-II & 0.0 & Flat \\
B4 & FX?-POOL & -0.004 & Spatially \\
VAD & VENUS-II & & \\
\hline & VENUS-II & -0.004 &
\end{tabular}

Initial Temp
Distribution

Doppler

Constant

Spatially

Spatially ependent

dependent 
This variation of case $A$ l was made only to remove a variable from the comparison and to observe the change in agreement, if any. A-3: FXE-POOL, FAD, and VENUS-II

In order to facilitate intercomparisons, including the FX2POOL code, the following two departures were made from case AI:

- Flat initial core temperature distribution i.e., all $\mathrm{UO}_{2}$ temperatures $=2500 \mathrm{~K}$.

- Initial delayed neutron precursor concentration corresponded to steady state at the initial power level, $1.7 \times 10^{6} \mathrm{MW}$.

A-4: PAD

This case was run after the initial analyses uncovered the heat capacity discrepancy. All input specifications are identical to the PAD A-l run except heat apacity. For this case only the heat capacity was set equal to $0.437 \mathrm{~J} / \mathrm{g}-\mathrm{K}$, the value used in ail FX2-POOL and VENUS-II calculations.

\section{B-1: PAD and VENUS-II}

This is the nominal base case B. Differences between the two analyses are the same as those listed for case Al.

B-2: PAD and VENUS-II

This is ldentical to case BI with the one exception:

- Doppler $=0.0$.

E-3: FX2-POCE, PAD, anc VENUS-II

As with cases $A I$ and $A 3$, the following two differences exist 
between $B I$ and $B 3$ :

- Flat initial core temperature distribution i.e., all $\mathrm{UO}_{2}$ temperatures $=1500 \mathrm{~K}$.

- Initial delayed neutron precursor coricentration corresponded to steady state at the initial power level, $1000 \mathrm{MW}$.

\section{B-4: VENUS-II}

This is identical to the Venus-II analysis of case Bl with one exception:

- The initial temperature profile was flatter than that employed in case $B I$ due to a higher base temperature specification.

Although the infitial temperature profile in this case was not judged to be as realistic for this case, the results are presented since they indicate the effect of this input specification on the fission energy release.

In mapping the specified $R-2$ reactor geometry onto the PAD spherical grid, masses and densities were conserved. Experience with PAD in calculating various severe reactor transient experiments (which had clearly nonspherfcal geometries) has shown that this is a more accurate approach in general than, for example, to conserve a characteristic dimension. The equivalent spherical radil employed in the $P A D$ calculations were thus:

Core Zone I o.d. $=124.26 \mathrm{~cm}$

Core Zone II 0.d. $=158.38 \mathrm{~cm}$

Reflector thickness $=10.56 \mathrm{~cm}$. 
The reflector material had the radial blanket composition listed in the Appendix. The thickness was chosen to give the destrea radial core power profile.

IV. RESULTS

The significant outputs from these disassembly calculations which are reported and compared are:

- fission energy

- energy in molten fuel

- kinetic energy/work

- power

- reactivity

- pressures and temperatures.

For all cases the energies and system maxima (power, reciprocal period (a), temperature) are listed in Table II. Examination of this tabje leads to the following significant observations:

- The one comparison which was made with consistent heat capacities, A-1 (VENUS-II) vs A-4 (PAD), showed excellent agreement in the fission energy deposition, 20.5\% difference.

- For all other PAD/VENUS-II comparisons there existed the heat capacity discrepancy. As indicated by the two $P A D$ runs, $A-1$ and $A-4$, and the sensitivity studies described in Ref. 6, the fission energy varies linearly with heat capacity for volded core disassembly calculations. It is then estimatec that using the same heat capacity would bring the PAD/VENUS-II agreemert in fission energy release. 
TABLE II

ENERGY RELEASES AND SYSTEM MAXIMA

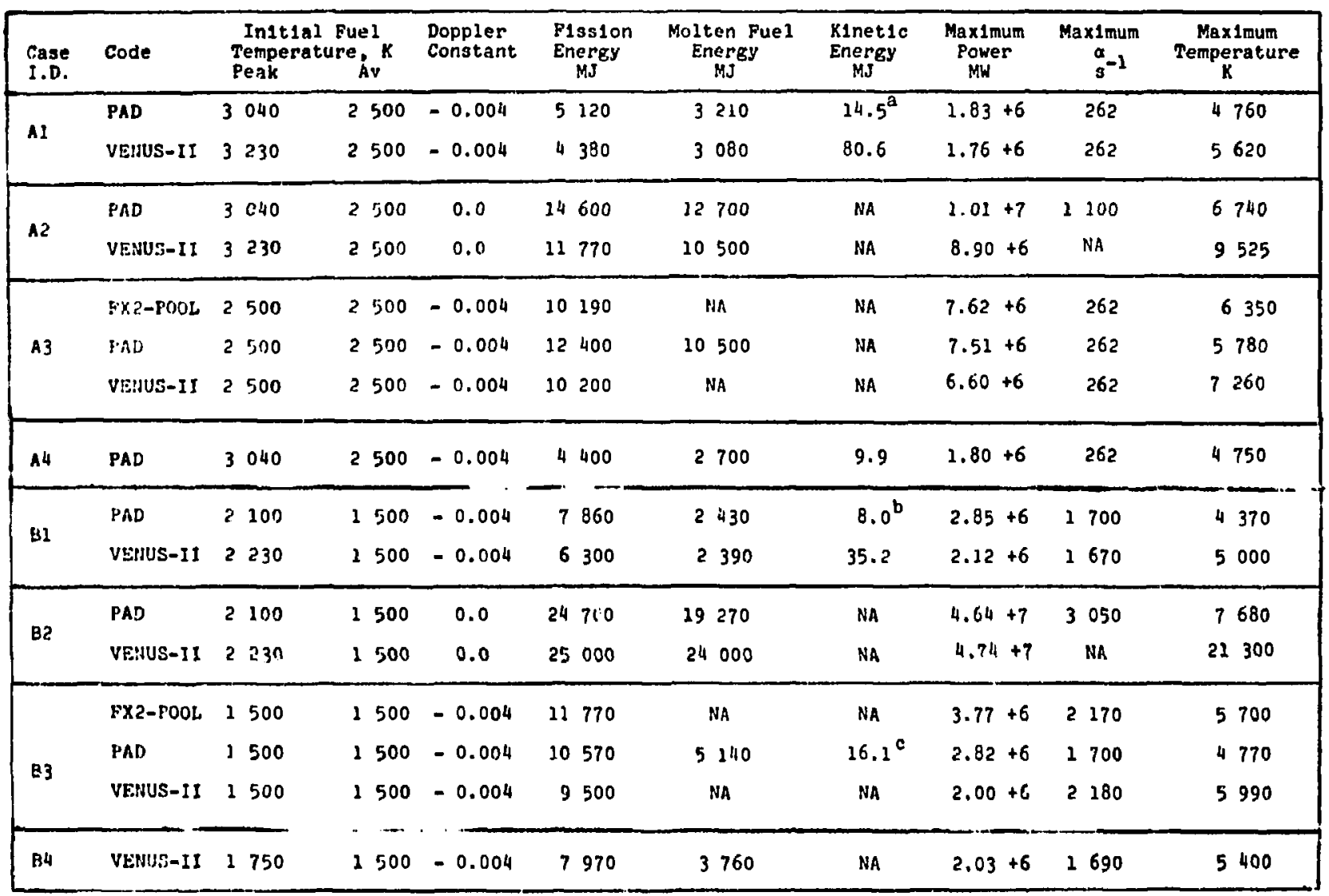

NA - Not Avallable. Core averaged fuel vapor pressure (at $V / V_{0}=8$ ). a. $5.2 \mathrm{~atm} ; \mathrm{b}=3.1 \mathrm{~atm} ; \mathrm{c}=6.4 \mathrm{~atm}$. 
within $\sim \pm 5 \%$ for all cases except B2.

- For cases $\mathrm{A} 3$ and $\mathrm{B} 3$ the FX2-POOL fission energies are in reasonab ${ }_{\perp}$ agreement with both the VENUS-II and PAD results. This is in spite of the FX2-IJOL model inadvertently using only one core enrichment zone and the very different Doppler treatments.

- VENUS-II fission energies as calculated by P. Abranson at ANL and $J$. Boudreau at LASL (case E3) were identical. In addition, for an entirely different VENUS-II problem, the same input deck when run at ANL, BYU, and LASL has yielded identical results to within the roundof $f$ and significant figure capabilities of the computers. 7

- Calculated kinetic energies are much less than the fission energies. Furthermore, in spite of the ract that $P A D$ calculates kinetic energy (which was evaIuated at a system volume expansion of 8 ) and VENUS-II calculates the work potential (evaluated via a cell by cell isentropic expansion to 1 atmosphere) the ifference between these quantities is still not large.

- Two cases, A2 and B2, had zero Doppler feedback. A1though relative agreement between $\mathrm{PAD}$ and VENUS-II fission energies was essentially the same as for all other cases, this may be simply the result of replacing one neutronic shutdown effect (Doppler) for another (displacement) when both effects are modeled differently in both codes. 
It should be emphasized that calculations (A2 and B2) are purely academic and were rur only to accentuate possible displacement feedback and/or high-energy density efiects. Obviously the former were similar (due to the relatively good agreement in total energy release). However, as brought out dramatically by the peak temperatures, the energy partition models in PAD and VENUS-II diverge considerably at these extreme energy densities. These zero Doppler comparisons accentuate the need to better understand the accuracy and range of applicability of the energy partition models in these codes.

In the following few pages the four cases $A 1, A 3, B I$, and B3 will be examined in some detail and in the above order.

\section{A-1: PAD and VENUS-II}

The power and net reactivity histories are shown in Figs. 2 and 3 , respectively. The slight differences between the pairs of curves may be explained by examination of Figs. 4 and 5 , the Doppler and displacement reactivity traces. Doppler feedback is initially stronger with VENUS-II. This is probably attributable to the higher temperatures calculated by VENUS-II for the same energy deposition, which in turn results from the lower heat capacity and energy partition model effecis. This results in a somewhat lower peak power. It is interesting to note that at about that time when all core regions have gone through the melt transition ( $-1.5 \mathrm{~ms}$ ) the calculated Doppler reactivities are nearly identical.

The power spike is turned over entireiy by Doppler feedback; however, neutronic shutdown results from the strong displacement 
reactivity feedback. This is similar for both codes up to about $3.5 \mathrm{~ms}$, at which time VENUS-II shows a much steeper reactivicy decrease. This is probably due to a combination of the higher peak fuel vapor pressures as well as geometric effects. This strong departure does not affect the total energy release by more than a few percent due to the already reduced power level at the time of this divergence. Due to the dominance of Doppler feedback for all realistic cases, the differing geometric feedbacks have little influence on the results.

Peak (core center) fuel temperatures and vapor pressures vs time are shown in Figs. 6 and 7 . The large divergence is die to a combination of energy partition model differences and peak-toaverage power profile differences in the one- and two-dimensional geometries. Perhaps most significant is the result that in spite of relatively large differences in peak temperatures and vapor pressures, core averaged properties, particularly Doppler feedback, are in good agreement. Thus global characterization of this contrived, severe disassembly accident is afforded by both codes. A-3: FX2-POOL, PAD, and VENUS-II

Power and reactivity histories are shown for this case in Figs. 8 and 9, respectively. The PAD-VENUS-II agreement is noticeably good. The initial agreement among all three codes is very satisfactory; however, due to a model limitation in FX2-PCOL and the initial specifications for this case, the net reactivity trace diverges from that of $P A D$ and VENUS-II at about $0.4 \mathrm{~ms}$. Recall that (1) case $A 3$ has a flat initial fuel temperature distribution and (2) FX2-POOL does not account for heat of fusion. The flattening of the net reactivity history between 0.4 and $0.8 \mathrm{~ms}$ results from 
the nearly zero Doppler feedback as large core reglons remain at the melt temperature for a few tenths of milliseconds. Although not explicitly shown on Fig. 9, displacement feedback remains nearly zero until $21.6 \mathrm{~ms}$ at which time it increases very quickly and controls the neutronic shutdown.

\section{B-1: PAD and VENUS-II}

Figures 10 and $I 1$ show the power and net reactivity histories for this case. As with case AI, these curves are most easily interpreted by examination of Figs. 12 and 13, which show the Doppler and displacement feedback reactivities as functions of time. Once again, the initial VENUS-II Doppler feedback is slightly larger than that calculated by PAD. The explanation is identical to that discussed under case $A l$. Once again the higher temperatures calculated by VENUS-II result in a somewhat lower peak power.

The individual and net reactivity feedback traces are very similar up about $7 \mathrm{~ms}$. At this time the Doppler feedback is diminishing due to the reduced power level, and the input reactivity ramp is causing the net reactivity to flatten or turn up slightly for about 2 or $3 \mathrm{~ms}$. At this time the displacement reactivity feedback begins to predominate and leads to neutronic shutdown.

The slight positive displacement feedback calculated by PAD which peaks around $7 \mathrm{~ms}$ (at a value of 0.02 dollars) results from the initial, inward motion of the interface between the two core zones. This effect is also present in the VENUS-II analysis; however, the positive radial feedback is less than the negative axial feedback, with the net displacement reactivity being monotonic. As with Case $A l$, the VENUS-II displacement reactivity eventually 
exhibits a much stronger time dependence than that of PAD. How-. ever, this occurs when the power excursion is essentially complete and thus it does not influence the total energy release.

Core center fuel temperature and vapor pressure histories are shown in Figs. I4 and 15. The divergence in these peak values was also noted in case $A l$ and qualitatively the explanation is the same. However, system-averaged properties agreed well and thus global characterization of this contrived, severe disassembly accident is also afforded by both codes.

$\mathrm{B}-3: \quad \mathrm{FX}-\mathrm{POOL}, \mathrm{PAD}$, and VENUS-II

This case affords a relatively clean comparison among the three calculational methods; thus it was decided to examine the power, reactivity, and temperature histories more closely and quantitatively. The power traces are shown in Figs. 16 and 17 and the reactivity traces in Fig. 18. It was expected that the initial power rise (until feedback effects become significant) would be very similar for all three codes. After significant temperatures and pressures were generated some departures in the power and reactivity curves were to be expected since Doppler and displacement reactivity feedbacks (among other effects) are modeled differently in all three codes.

It appears that the PAD and VENUS-II power and reactivity curves are internally consistent, at least up to the time of peak power for the first power spike. A very small difference in the delayed neutron fraction $(25 \%)$ between these two codes results in the PAD absolute reactivity (not in dollars) being slightly larger than that of VENUS-II through the first few milliseconds. This qualitatively 
explains even the relatively minor PAD and VENUS-II power profile differences for these early times. The apparent anomaly between FX2-POOL and the other two codes during the first few milliseconds has the following explanation.

Although the specifications for the kinetics parameters, delayed neutron fraction, and neutron lifetime are listed in Appendix A, FX2 calculates and uses its own prompt neutron lifetime and employs a slightly different delayed neutron fraction. VENUS-II and PAD, on the other hand, require as input the neutron lifetime. Thus, differences in this basic parameter could explain the initial power divergence of FX2-POOL. Upon investigation of the prompt neutron lifetime calculated by FX2, the value of $0.401 \mathrm{~ms}$ was uncovered. This lower lifetime is sufficient to explain the peak power anomaly. In order to quantify the explanation one can, to first order, neglect delayed neutrons and from the point kinetics equation arrive at the relationship

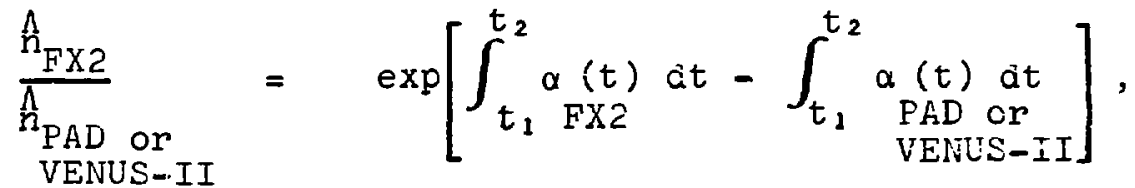

where $\hat{n}=$ peak neutron density or power

$\alpha=\Delta \mathrm{k} / \ell=$ prompt reciprocal period

$t_{1}=0$ for this case, and

$t_{2}=$ the time of peak power, i.e., when system reactivity passes through zero.

A hand evaluation of the areas under the reactivity curves in Fig. 18 and using the specified prompt neutron lifetime of 0.6 


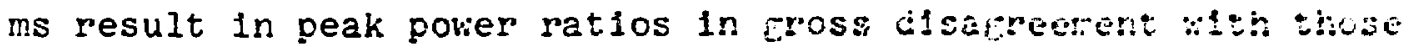
obtained from FIE. 17. Honever, using these same internatca reactivities, but lifetines of $\mathrm{c} .401$ and $0.6 \mathrm{~ms}$, :espectively, for FX2-POOL and either FAD or VENTS-II, results In predicted fear power ratios in satisfactory arreanent with those from 10.17 .

\section{Temperature Discrepancy}

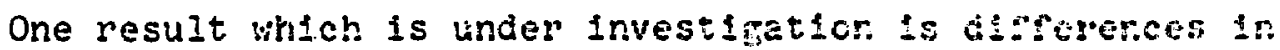
peak (core center) temperatume. Constder, son example, the peat: temperatures and total isston enereles of case 33 , repented hrot for clarity.

\section{FISSIO: EHERGY}

(iv)

11770

10570

500
PE⿱

FX2-PCOL

PAD

VENUS-II
5700

4770

5990

Recall that FX2-POOL does not account for heat of fusion and its calculational model inadvertently had only one core enrichrent zone. Both of these differences, relative to VEUS-II and FAD, wolld terd toward higher peak temperatures for FX2-FOOL. Another point is that FX2 calculates its own power distribution and VEHUS-IT and PAD employed an input distribution from a prior k-calculation. Fhis latter effect should be very minor.

Heat of vaporization effects (which the VENiUS-II calculations did not account for) act in the opposite direction; they would tend toward higher peak temperatures for VENUS-II. These individual effects will be eliminated where possibie in future comparisons and otherwise quantified in order to enable a more precise and complete understanding of the calculated temperatures. 


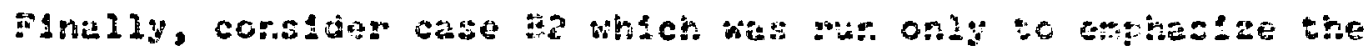

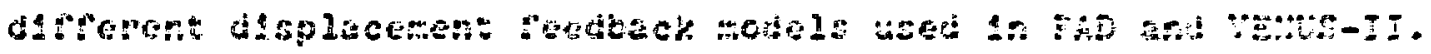

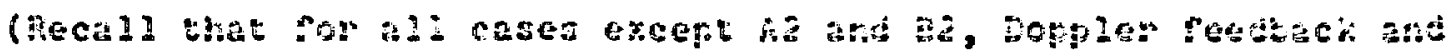

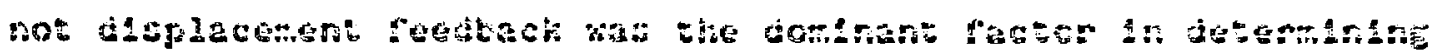

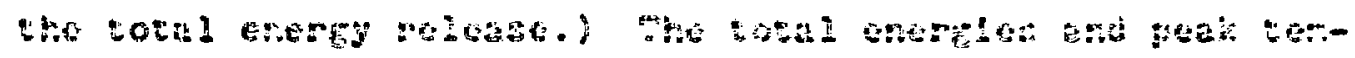

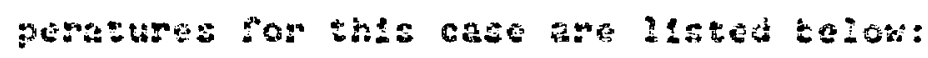

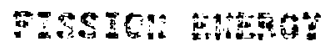

(Wi)

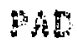

visutis
2400

25000
Font

$(\because)$

7600

21300

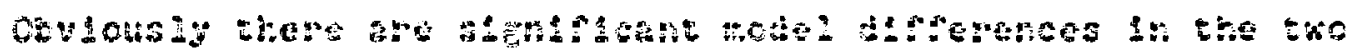

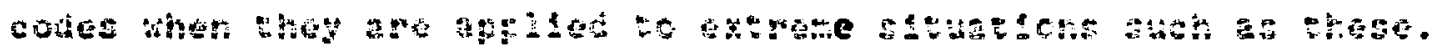

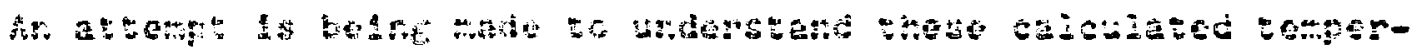
atures.

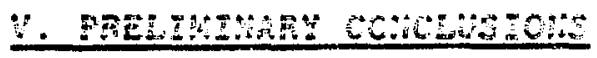

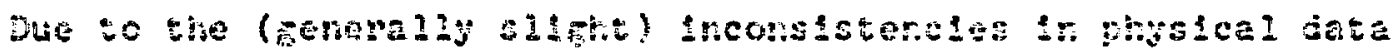
and in the peonetric and watentat noceis present in these tnital compansor. calculations, any conclustons shculd be consfored ten-

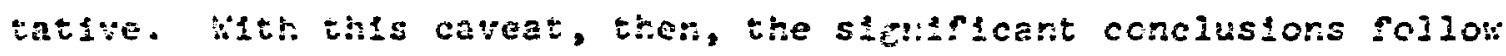
cirectely from the reasons bhy this stucy was felt to te vorthinile, as stated in the introduction.

- All three calculational methods are internaliy consistent in predictirg the total energy deposfted in the fus?, at least for the models and other specified conditlors employed herein.

For similar total energy depositions, calculated (peak) temperatures diverge rather strongly, the afvergerce increasine monotonically with fiel internai energy. Thes is 
due to the inherently different energy-temperature relationships in the codes. It appears that heat of vaporization effects may largely account for these differences, which are currently being investigated.

Kinetic energy and work potential, which are measures of the damage potential of an excursion, are orders of magnitude less than the fission energy.

\section{FUTURE EFFORTS}

Prior to analyzing the results presented herein it was clanned to perform comparison calculations for some of these same cases but at input reactivity irsertion rates of 20 and 200\$/s. These calculations will still be made and should provide useful information relative to the range of appilcability of these three computational methods. First, however, an attempt will be made to better and more completely document and understand at least one case, e.g., B3. Here particular reference is made to fuel temperatures as calculated by the different codes. 


\section{REFERENCES}

1. W. R. Stratton, L. B. Engle, and D. M. Peterson, "Reactor Power Transient Studies," International Conference on Engineering of Fast Reactors for Safe and Rellable Operaition, Karlsruhe, Germany, Oct. 9-13, 1972.

2. D. A. Meneley, G. K. Leaf, A. J. Lindeman, T. A. Daly, and W. T. Sha, "A Kinetics Mcdel for Fast Neutron Analysis in Two Dimensions," Symp. on Dynamics of Nuclear Systems, Tucson, Arizona, Nov. 23-25, 1970.

3. W. T. Sha, T. A. Daly et al., "Two-Dimensional Fast Reactor Disassembiy Analysis with Space Time Kinetics," AnS Topical Meeting on New Developments in Reactor Mathematics anc Applications, Idaho Falls, Narch 24-31, 1971.

4. P. B. Abramson, "POOL-A Two-Dimensional Three-Component Coupled Hydrodynamic Thermodynamic Computer Model for Boiling Pools of Fuel and Steel," Argonne National Laboratory report RSA-TM-3 (May 1975).

5. J. F. Jackson and R. B. Nicholson, "VENUS-II: An LMFBF Disassembly Program," Argonne National Laboratory report ANL7951 (September 1972).

6. R. B. Nicholson and J. F. Jackson, "A Sensitivity Study for Fast-Reactor Disassembly Calculations," Argonne National Laboratory report ANL-7952 (January 1974).

7. J. F. Jacksor, Brigham Young University, personal communication, August 1975. 


\section{APPENDIX}

With the exception of the cellwise reactivity vorths and spec1fic powers which were necessary for the Vel:Us-II calcliations, all other reactor and nuclear data are Etven below. The former are avallable, but too cumbersome to be conveniently reported.

1. Reactor Power

Core

Axial Elanket

Radial Blanket

Total

2. Core Dimensions (Nominal)

Core Height

Core Zone 1 o.d.

Core Zone 2 o.d.

Axial Blanket Height (upper, lower, each)

Radial Blanket Height

Radial Blanket Thickness

Core Volume

3. Core Average Composition (vol\%)

Fuel

30.8

Steel
$840 \mathrm{Mb}$

32 "

$63 "$

$935 "$

$$
\begin{aligned}
& 76 \mathrm{~cm} \text { (30 in.) } \\
& 130 \mathrm{cr} \text { (51 in.) } \\
& 185 \mathrm{~cm} \text { (73 in.) } \\
& 38 \mathrm{~cm}(15 \text { in.) } \\
& 152 \mathrm{~cm}(60 \text { in.) } \\
& 35 \mathrm{~cm}(14 \text { in.) } \\
& 2100 \text { liters }
\end{aligned}
$$


Sodium

40.7

Beo \& Control

4.8

4. Radial Elanket Composition (yol:)

$\mathrm{UO}_{2}$ (natural)

49.5

Steel

18.9

Sodium

31.6

5. Nuclear Data

Average Enrichment, $\%$ Fissile $\mathrm{Pu}$ in

$17 \cdot 2$

Total $(\mathrm{Pu}+\mathrm{U})$

Fissile Inventory

Core

969

Axial Blanket

89

Radial Blanket

267

Total

$1325 \mathrm{~kg}$

Fuel (core) smear density

$90 \%$

Fuel mass, $(\mathrm{U}+\mathrm{PU}) \mathrm{O}_{2}$

$6500 \mathrm{~kg}$

Doppler Value ( $T \mathrm{dk} / \mathrm{dT}$ )

Sodium-in
Sodium-out (blankets \& core)

$-0.0060$

$-0.0040$

6. Point Kinetics

Neutron lifetime

6.0 E-7 s

Precursor groups

6

Delayed Neutron Fractions

$7.9 \quad E-5$

6.87 E-4 


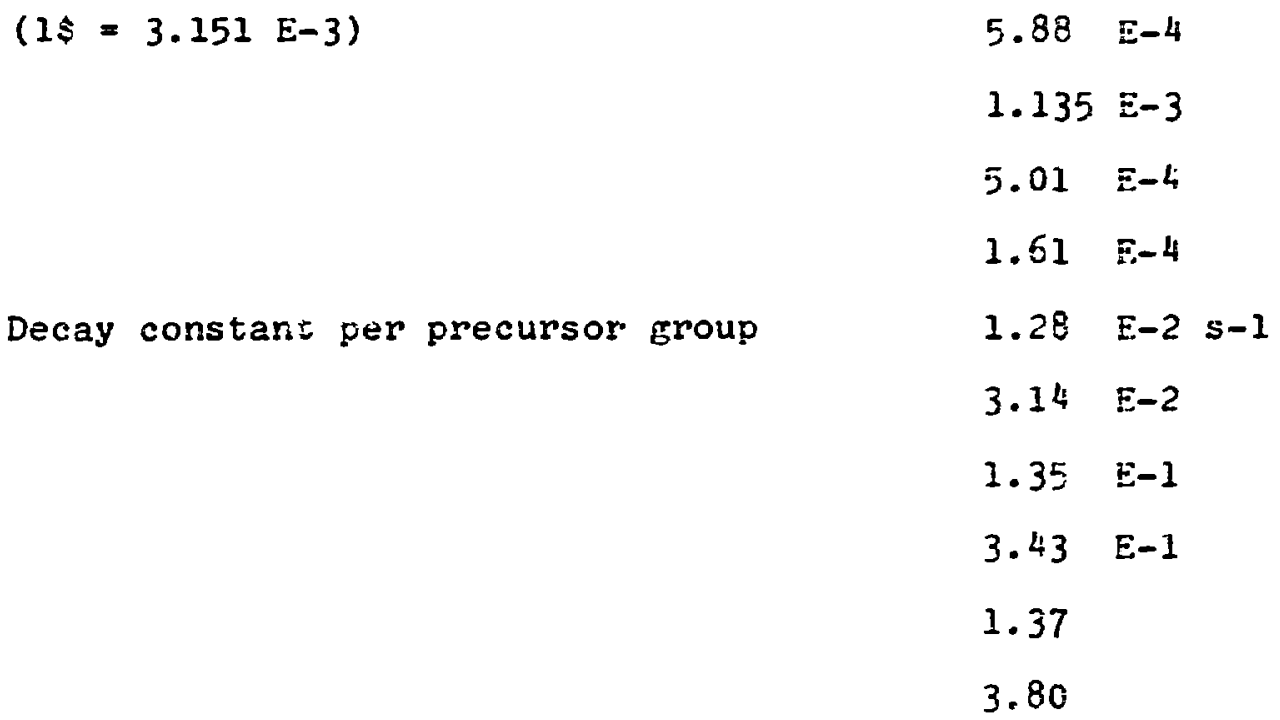




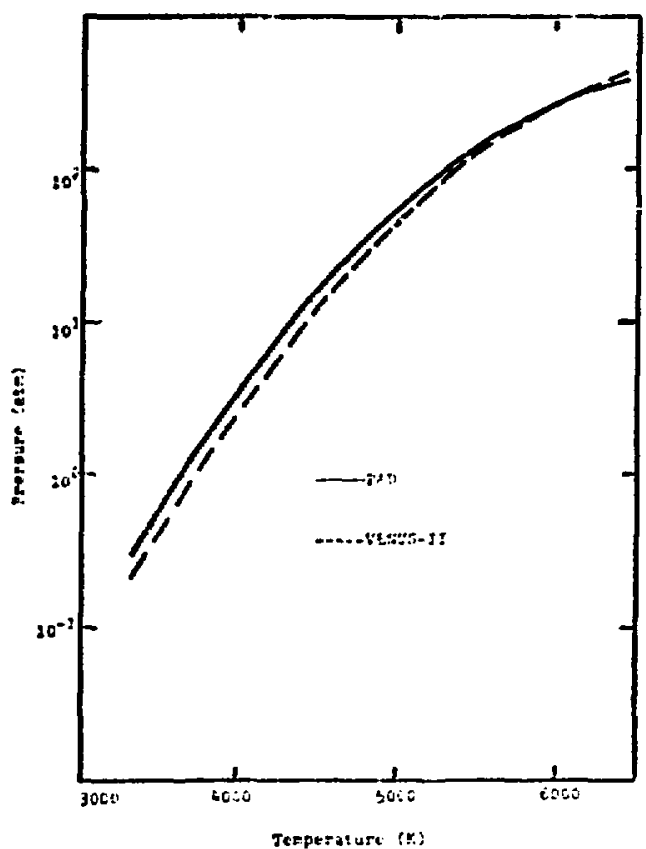

FIE. 1. Saturated $: 0$ vapor pressure dependence on temperatire.

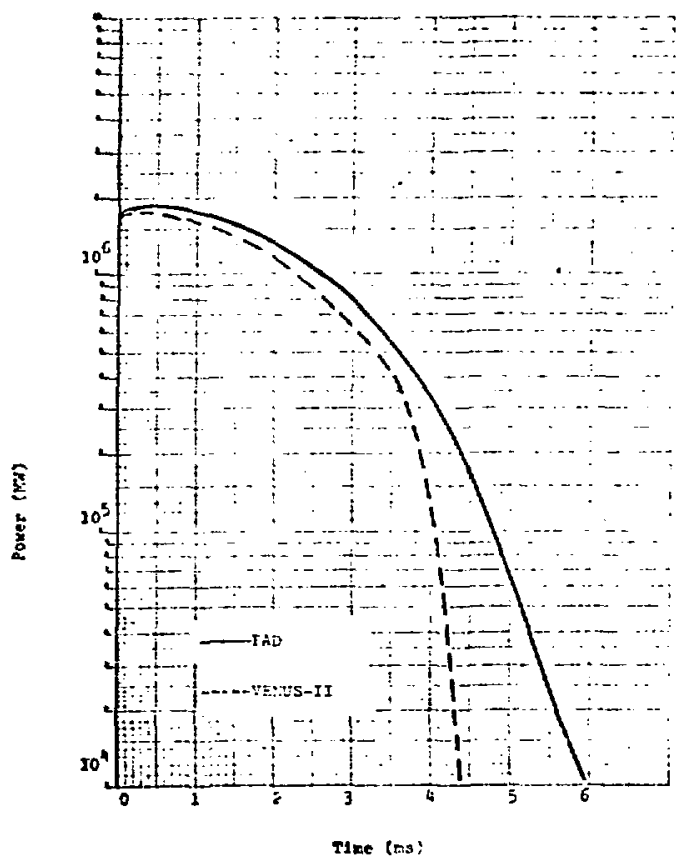

Fig. 2. Fower history for case Al.

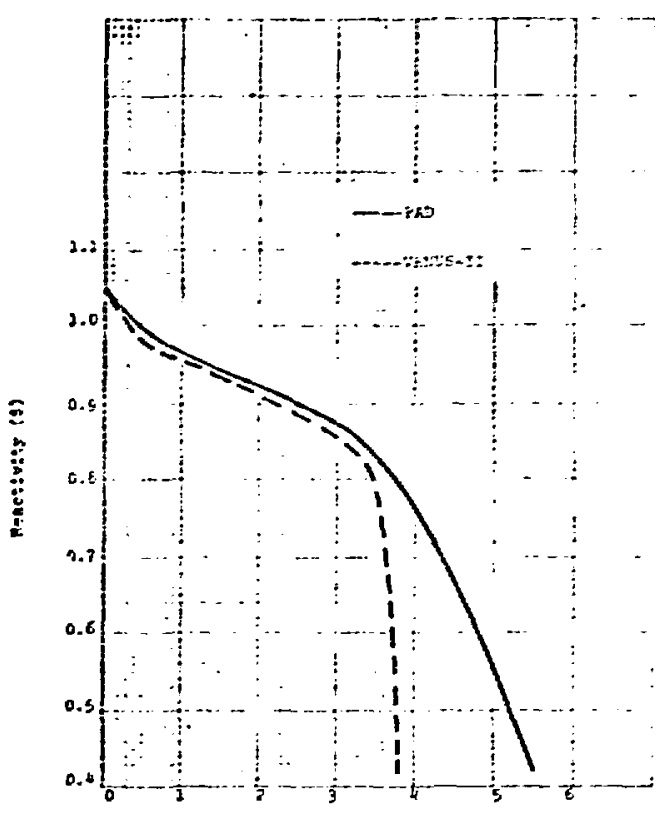

T2xe (as)

EIg. 3. Net reactirity, case $A 1$.

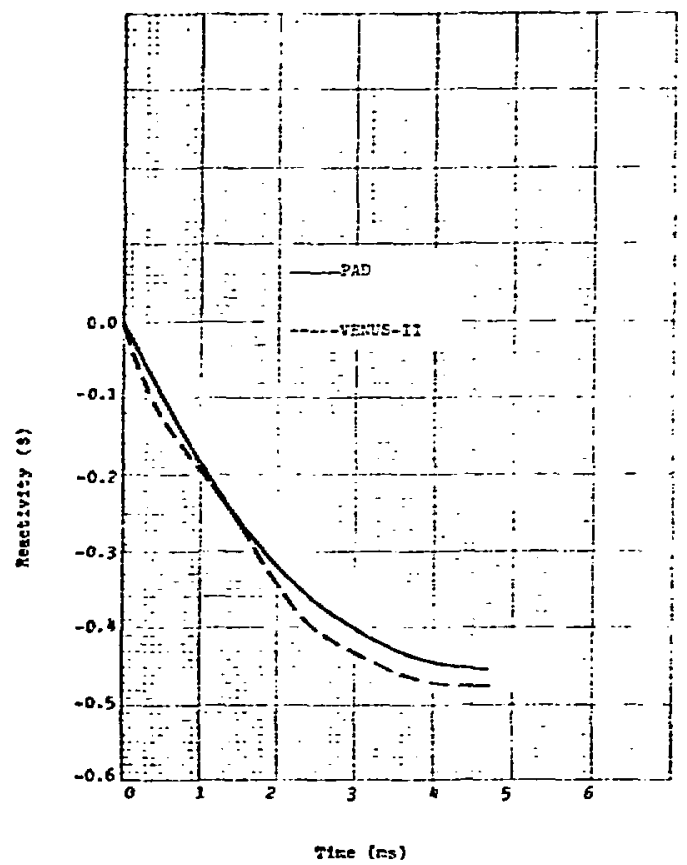

Fig. 4. Doppler reactivity, case $A 1$. 


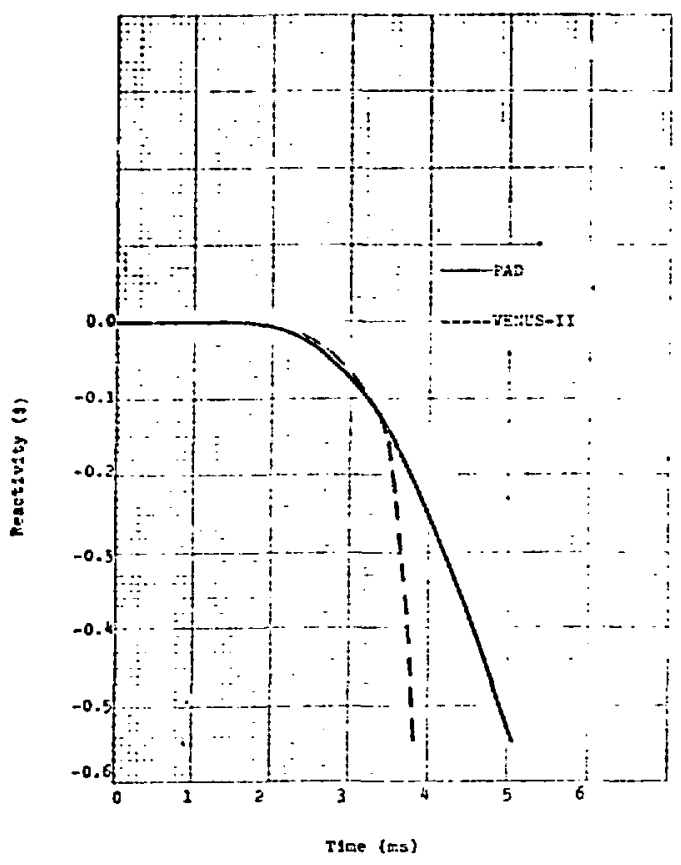

Fig. 5. Displacement reactivity, case AI.

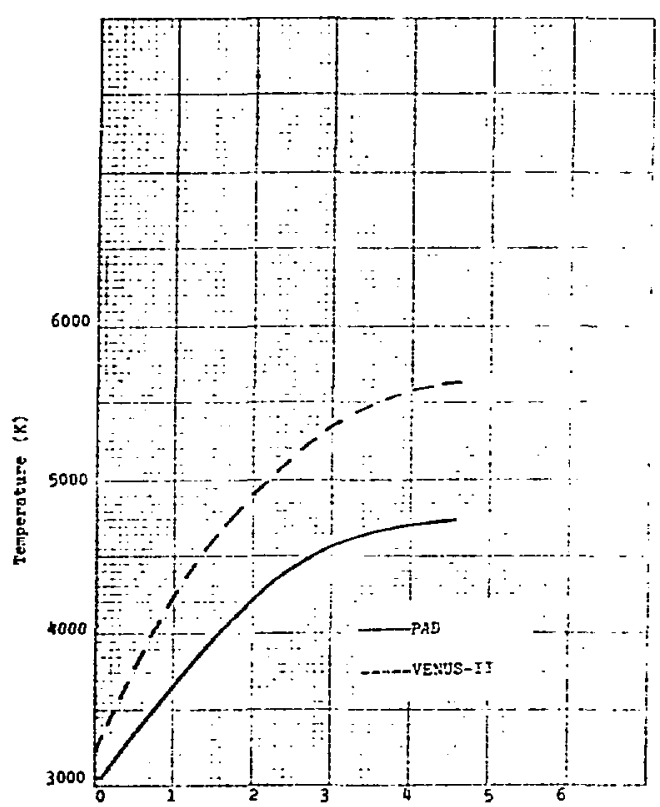

$\operatorname{Time}(\mathrm{ms})$

Fig. 6. Core center fuel temperature, case A. .

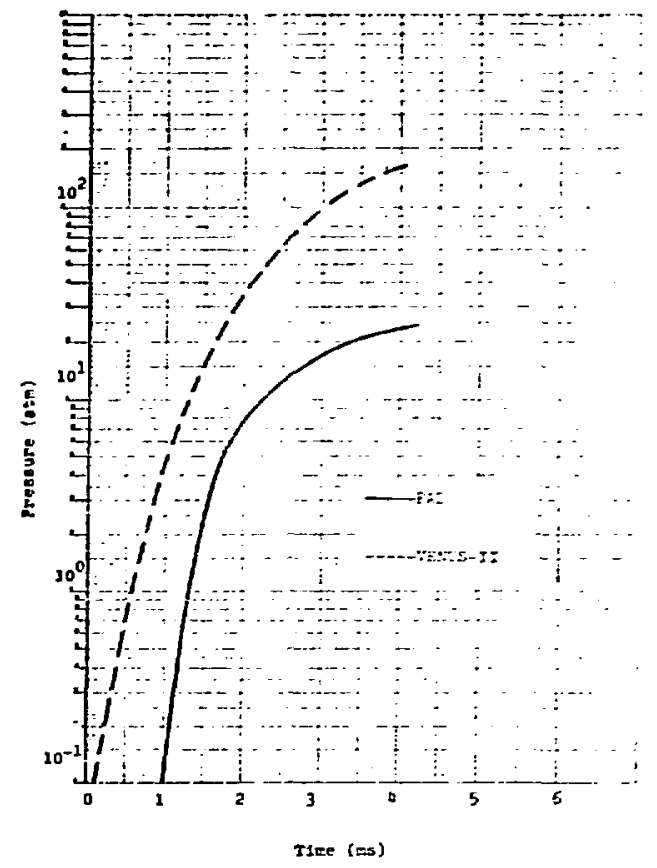

Fig. 7. Core center fue: yapor pressure, case Al.

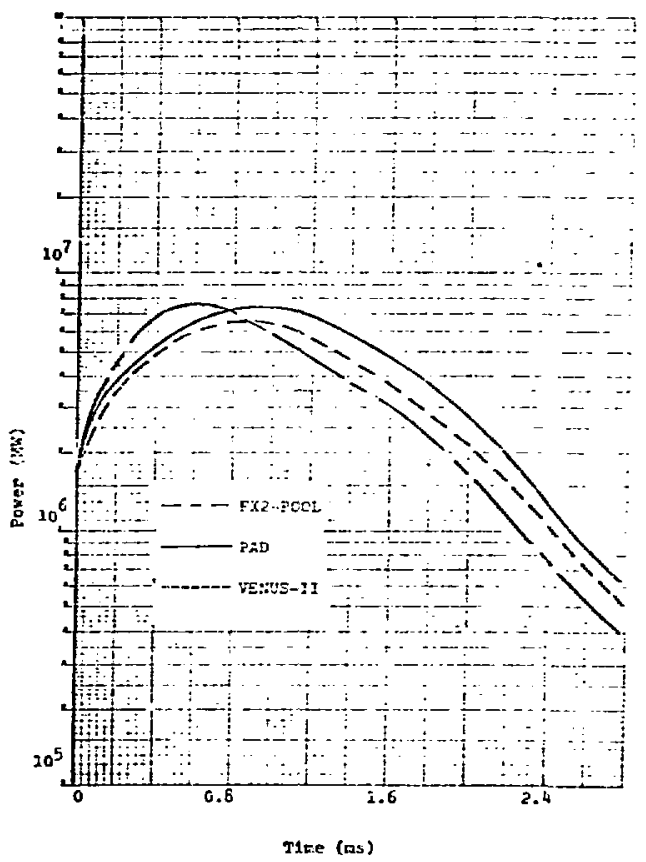

Fig. 8. Power histories, case 43. 


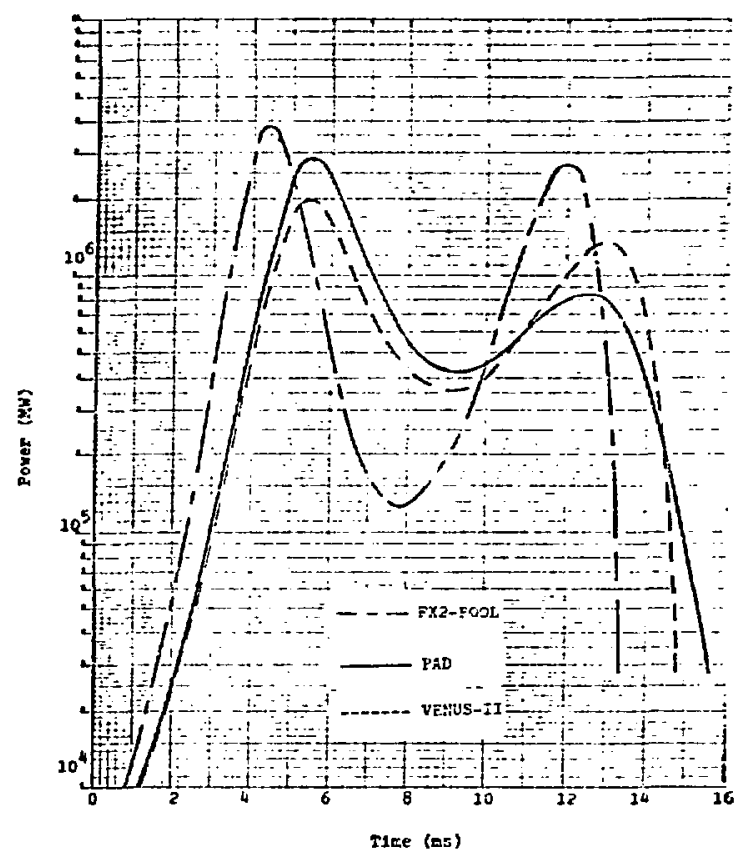

Fig. 17. Power history, case B3.

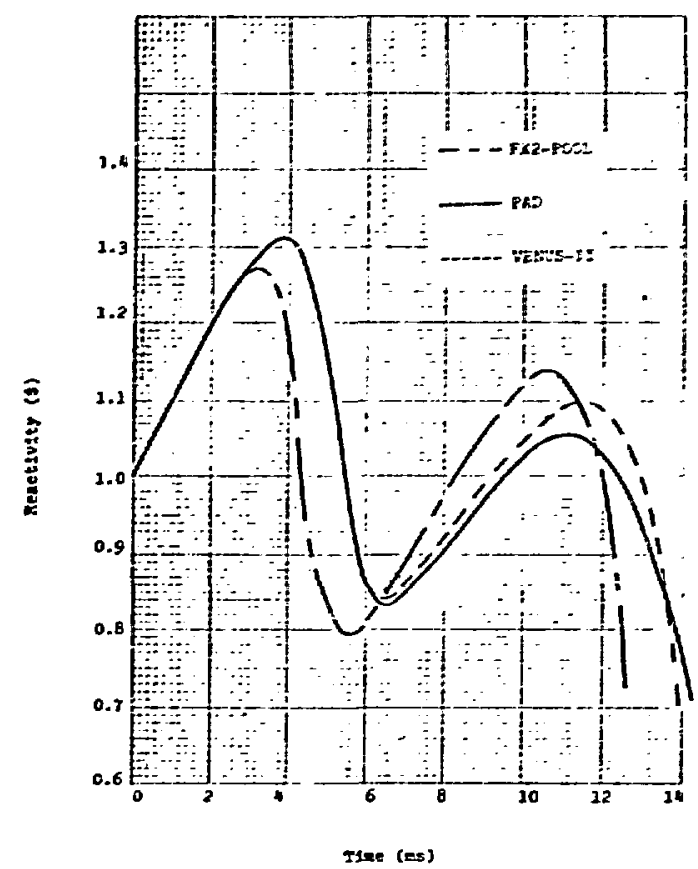

Fig. I8. Net reactivity, case $\mathrm{E} 3$. 


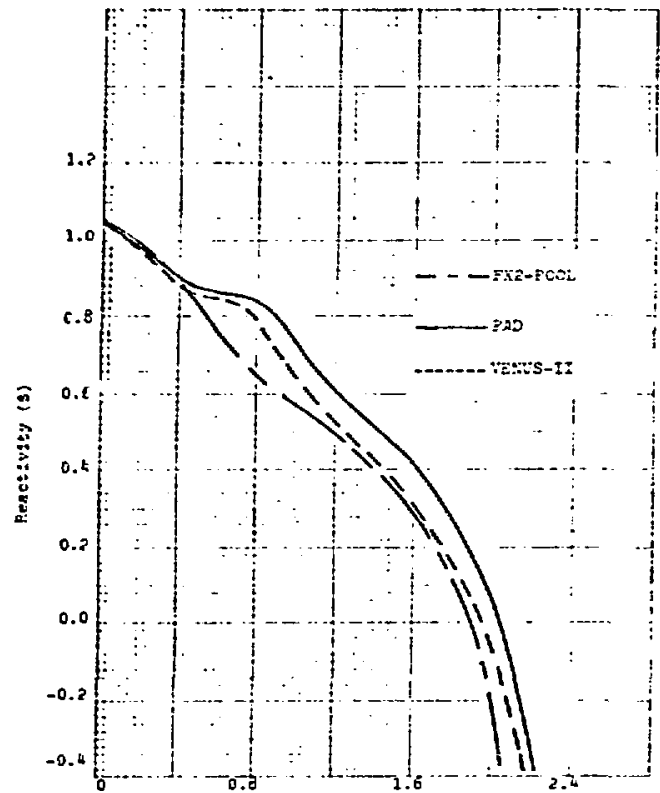

gite (n)

$=15$. 9. iet reactivity, case A3.

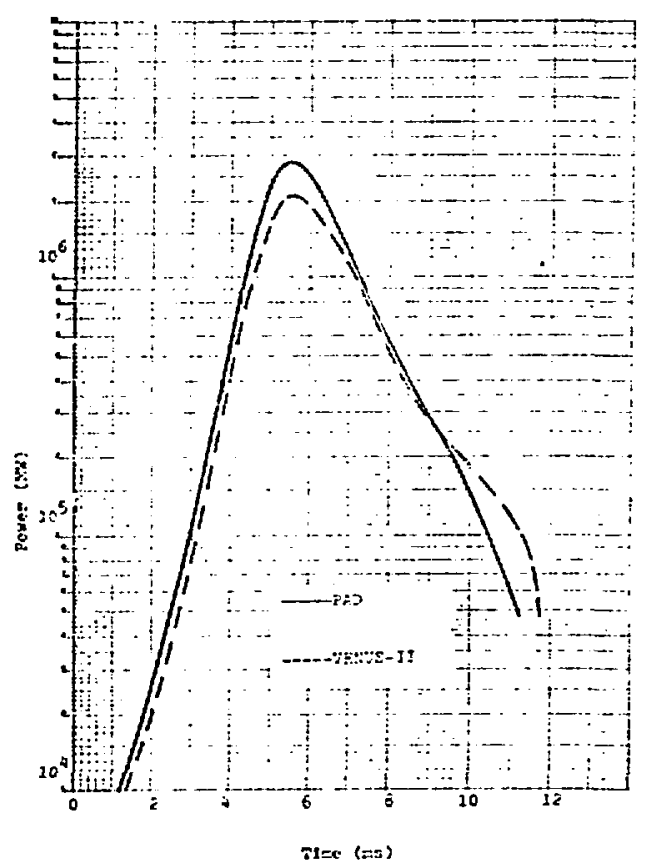

Fis. 1C. Poirer histories, case El.

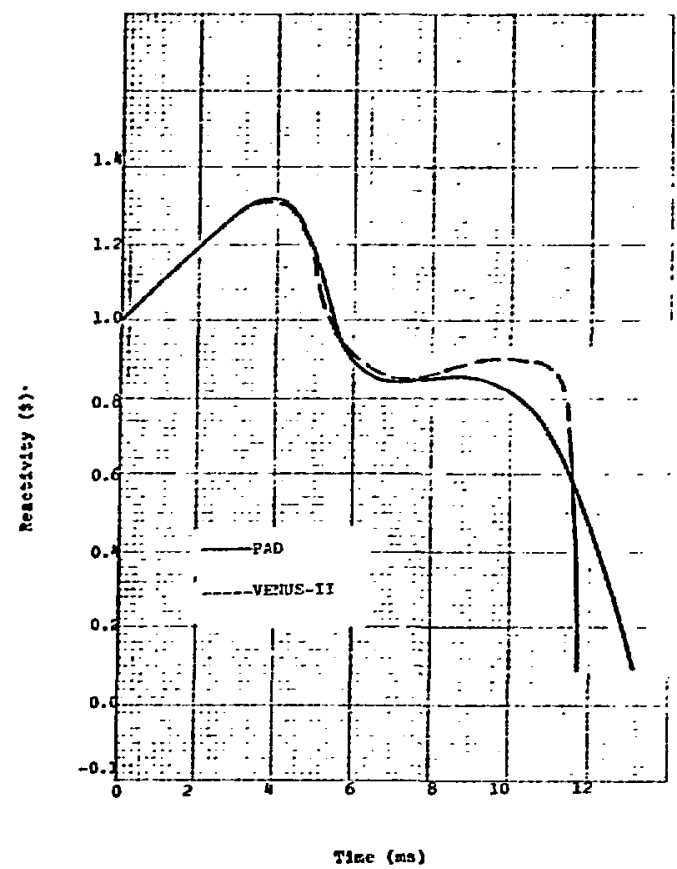

Fig. 11. Net reactivity, case $\mathrm{Bl}$.

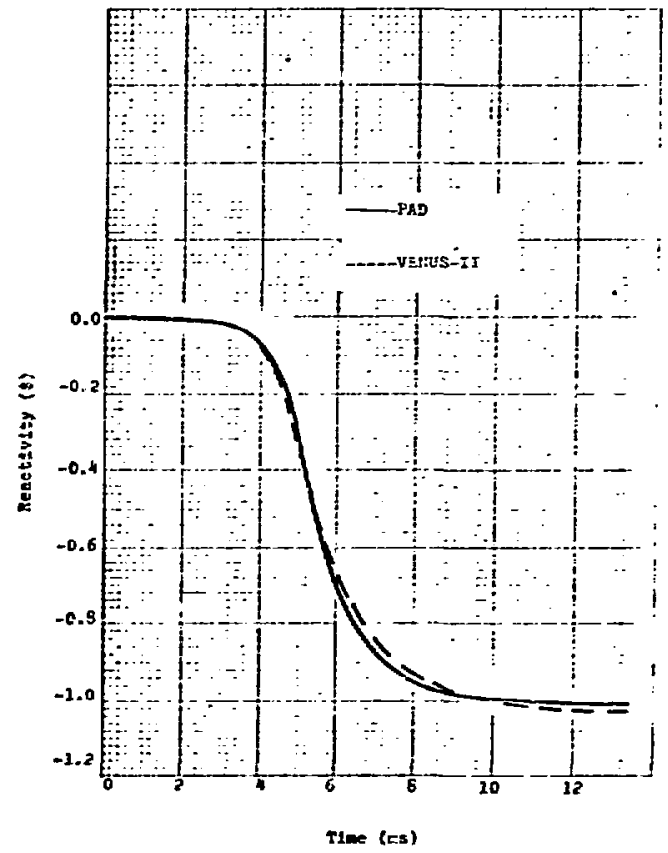

F\$5. 12. Doppler reactivity, case $\mathrm{Bl}$. 


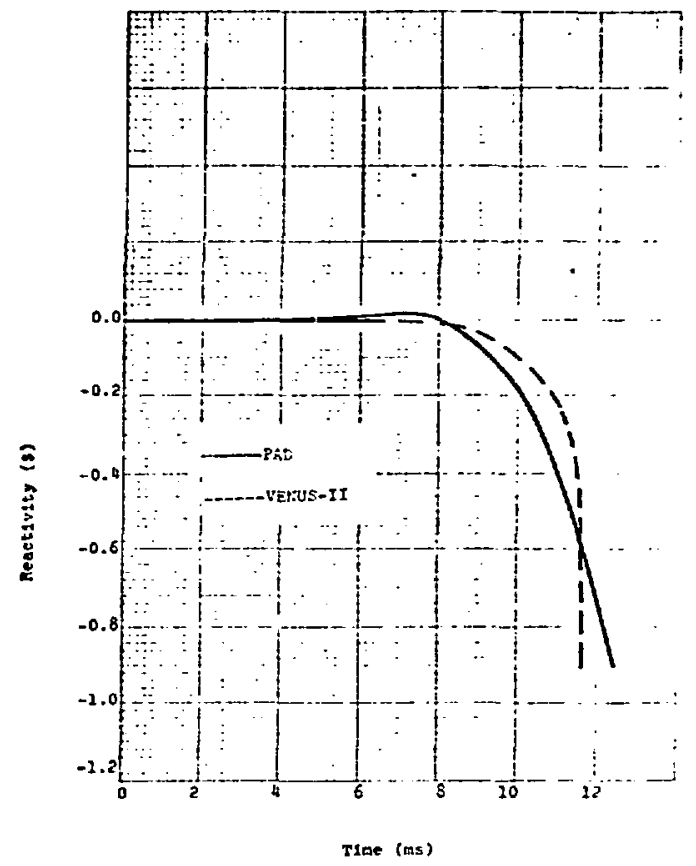

FIE. 23. DIsplacement reactivity, case $Z I$.

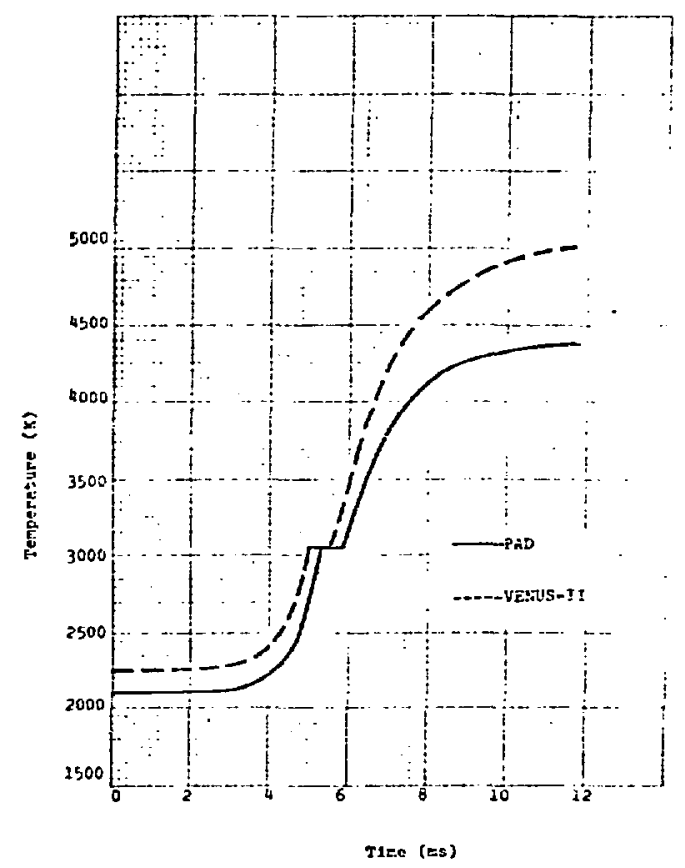

Fig. 14. Core center fuel temperatire, case Ei.

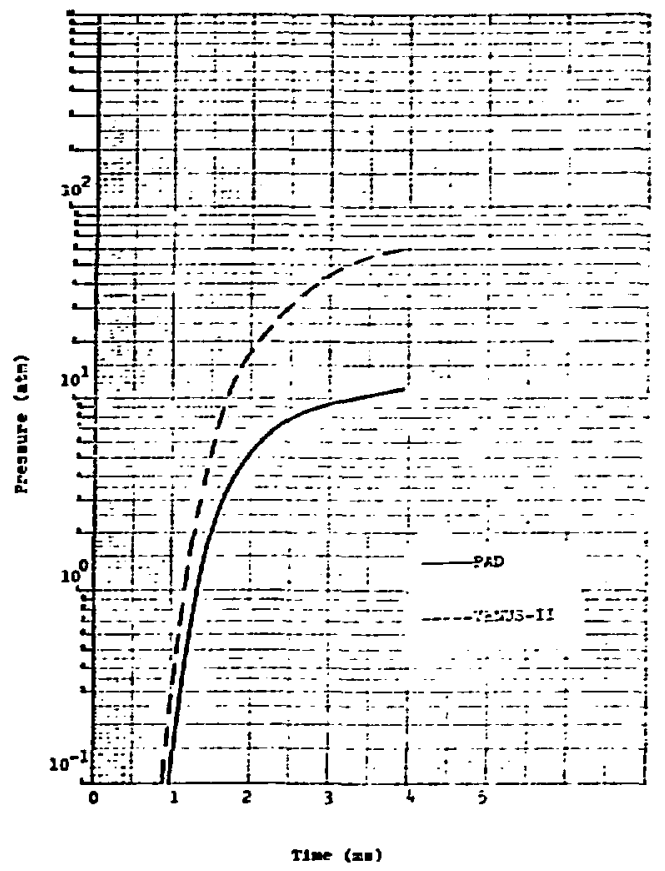

Fig. 15. Core center fuei pressure, case BI.

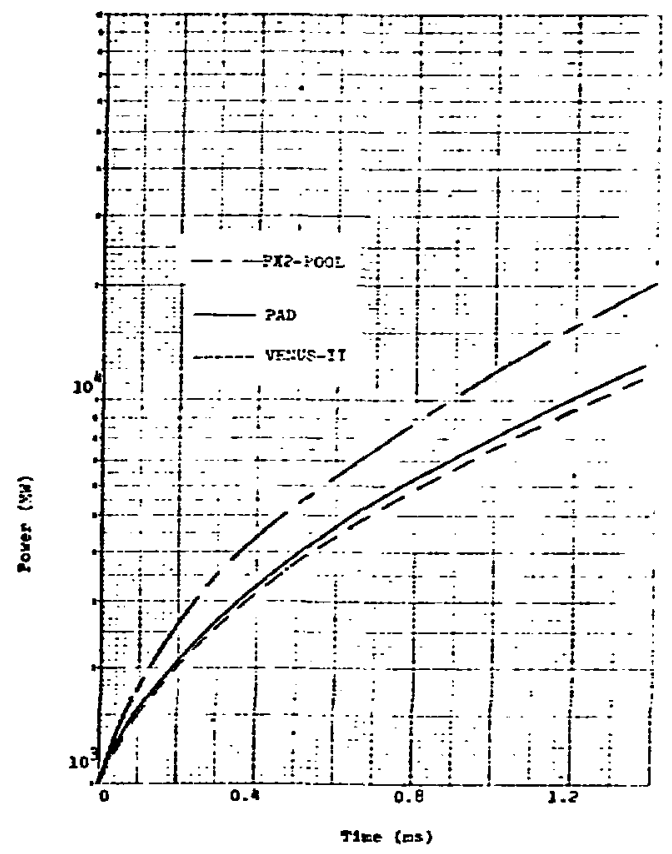

Fig. 16. Power history, case B3. 